\title{
MELATONIN SECRETION RHYTHM AND G PROTEIN MUTATIONS OF PATIENTS WITH OVARIAN AND BREAST CANCER
}

\author{
O. Palabiyik* ${ }^{*}$ T. Sipahi \\ Department of Biophysics, Faculty of Medicine, Trakya University, Edirne, Turkey
}

\begin{abstract}
PURPOSE: This study was designed to investigate the rhythm of melatonin secretion in the ovarian and breast cancer patients and the potential at the disease mechanism of mutation $\mathrm{G}_{\mathrm{i} 2 \alpha}$ (gip) that to clarify the role of $\mathrm{G}$ proteins.

METHODS: Subjects were recruited from patients attending Department of Obstetrics and Gynecology (Group 1; n=13, with ovarian cancer) and Department of General Surgery (Group 2; n=13, with breast cancer) of Trakya University School of Medicine. In addition to the control group (Group 3; $n=13$ ) was created from healthy individuals with the appropriate age and gender. From all subjects, venous blood samples were taken during the night at 22:00, 24:00, 02:00, 04:00 and 06:00 o'clock. Melatonin levels in the serums were measured by the RIA method. Additionally, In order to examine of $\mathrm{G}_{\mathrm{i} 2 \alpha}$ mutation, DNA were obtained from the tissue samples that were taken from ovarian and breast cancer patients. Of the $\mathrm{G}_{\mathrm{i} 2 \alpha}$ involving two location in both 179 and 205 codons and involving locations in 179 and 205 codons were separately quantified by polymerase chain reaction (PCR) using specific primers. Mutations were identified with the single-strand conformation polymorphism (SSCP) method. The potential role of the Gprotein mutation on the disease mechanism was researched.

RESULTS: In the study, the melatonin levels patients of ovarian and breast cancer compared to control group were found to difference. In control group, melatonin levels increased during the night, and started to decrease from early in the morning. In contrast, in the cancer patient group, irregular increases and decreases in melatonin levels was observed. Additionally, $\mathrm{G}_{\mathrm{i} 2 \alpha}$ (gip) mutations were observed in $15 \%$ of ovarian and $7 \%$ of breast cancer patients.

CONCLUSIONS: Melatonin works through distinct second messenger pathways to reduce cellular proliferation and to induce cellular differentiation. $\mathrm{G}$ protein-coupled receptors, including the Melatonin receptors, exist in living cells. Melatonin is effective in suppressing neoplastic growth in a variety of tumors like breast and ovarian cancer.
\end{abstract}

Key words: Melatonin, G protein, mutation, ovarian cancer, breast cancer

\section{INTRODUCTION}

Melatonin is a hormone that is secreted primarily by the pineal gland in response to darkness. As such, melatonin levels rise and fall throughout the night and day, respectively. [1, 2]. It is effective on biorhythm. It plays important roles in many physiological processes with its varying levels in the plasma. Many factors affect the synthesis and the release of melatonin in the pineal gland, hence the plasma melatonin level [3]. The well known and the most influential of among these factors is the light status of the medium (i.e. luminousness or darkness) [4]. Furthermore the age of the

* Correspondence to: Dr. Orkide Palabiyik, Department of Biophysics, Trakya University Faculty of Medicine, Edirne, TURKEY, Phone: + 9053258845 51,e-mail:orkide_69@hotmail.com individual, the season, the ambient temperature, hormones and magnetic fields also affect the plasma melatonin level [4]. While synthesis and release increase with the stimulating effects of the signals coming from

the superior cervical ganglion on pinealocytes in the dark, they decrease in the luminousness. Melatonin functions with three types of receptors on the cell membrane. These receptors are $\mathrm{MT}_{1}$ (high affinity [picomolar]), $\mathrm{MT}_{2}$ (low affinity [nanomolar]) and $\mathrm{MT}_{3}$ receptors which have been found recently $[5$, $6]$. The molecules having duty in the signal transduction systems and transferring the signals that they have received from the melatonin receptors into the cell are heterotrimeric $\mathrm{G}$ proteins. It has been detected $\mathrm{G}$ proteins are formed of three subunits $(\alpha, \beta$ ve $\gamma$ ) [7]. The recently obtained information 
concerning the structure and the function of the components of the signal transduction system by means of G-proteins prompt that the disorders in these components may lead to diseases [7, 8]. The fact that there is a probable relationship between the tumor development and the products released by the pineal gland has been shown in many various studies [9-11]. It has been detected that the suppression of the function of the pineal gland plays role in the etiology of the breast cancer, that of ovary cancer, that of prostate cancer and that of malign melanoma [12-14]. Many studies concerning pineal and immune function disorders in patients with cancer have been conducted and, it has been stated that the reduction in the serum melatonin level may be a clue for the malignancy [15]. Many studies have reported that there is a reduction in the release of melatonin in patients with breast cancer and ovary cancer [15-17].

The aim of this study is to examine the rhythm of melatonin release in patients with breast cancer and ovary cancer and furthermore, to investigate its potential in the disease mechanism by studying the mutations of $G_{i 2 \alpha}$ (gip) playing role in the signal transduction systems achieved by means of $G$ protein.

\section{MATERIAL METHODS}

\section{Patient population}

Local ethics committee approval was obtained before the study. Subjects was recruited from patients attending Department of Obstetrics and Gynecology (Group 1; n=13, with ovarian cancer) and Department of General Surgery (Group 2; n=13, with breast cancer) of Trakya University School of Medicine. In addition to the control group (Group 3; $n=13$ ) was created from healthy individuals with the appropriate age and gender.

\section{Blood Assays}

From all subjects, venous blood samples were taken during the night at 22:00, 24:00, 02:00, 04:00 and 06:00 o'clock. Melatonin levels in the serums were measured by the RIA method using kit. (DDV Biochemie GmbH, Austuralia).

\section{DNA Isolation}

DNA isolation was obtained from $2 \mathrm{ml}$ blood samples taken from the patient and control groups into the tubes with EDTA by using kit (Roche, Germany). The quality of the obtained DNAs was studied in $0.8 \%$-agarose gel. The quantities of DNA were computed through the ratio of absorption values measurements at 260 nanometers and at 280 nanometers.

\section{Polymerase Chain Reaction (PCR)}

The examined DNA regions of the gene encoding $G$ protein were amplified via polymerase chain reaction (PCR). In order to identify gip mutations related with $\mathrm{G}_{\mathrm{i} 2 \alpha}$, three separate regions were amplified. Exon 5 and 6 regions (604 bp to include intron region inside) of $\mathrm{G}_{\mathrm{i} 2 \alpha}$, exon 5 region ( $165 \mathrm{bp}$ including codon 179) and exon 6 region (175 bp including codon 205) were amplified by using $1 X$ PCR buffer in PCR $50 \mu \mathrm{l}$ reaction volume and by using $2-\mathrm{mM}$ $\mathrm{MgCl}_{2}$ for primary (10 pmol), dNTP $(0.2 \mathrm{mM})$, DNA (200 ng), Taq DNA polymerase (2.5 units) and exon 5 region and exon 6 region of $\mathrm{G}_{\mathrm{i} 2 \alpha}$ they were amplified for exon 5 and exon 6 regions by using $1.5-\mathrm{mM} \mathrm{MgCl}_{2}$.

Used primaries: for the region containing exon 5 and exon 6:

F: 5'-ATTGCACAGAGTGACTACATCCCC-3'

R: 5'-GGCGCTCAAGGCTACGCAGAA-3'

For exon 5 (codon 179):

F: 5'-CCCAGCTACCTGAACGACCTGG-3' R: 5'-CTCGCTCACTTGAAGTGTAGGTC-3'

For exon 6 (codon 205):

F: 5'-CATCTGCAGGATGTTTAGTGTGG-3'

R: 5'-CATCCTCTCACCATCTCCTCG-3'

PCR were established as thirty loops in a fashion that one minute at $94^{\circ} \mathrm{C}$, two minutes at $58^{\circ} \mathrm{C}$ and three minutes at $72^{\circ} \mathrm{C}$ for the region including exon 5 and exon 6,30 seconds at $94^{\circ} \mathrm{C}, 45$ seconds at $61^{\circ} \mathrm{C}$ and 45 seconds at $72^{\circ} \mathrm{C}$ for exon 5 and exon 6 regions.PCR products were studied under UV light in $2 \%$ agarose gels by running at $100 \mathrm{~V}$ and by staining with EtBr.

\section{SSCP (Single Strand Conformation Polymorphism)}

A single nucleotide difference in the DNA piece sequence having a certain conformation causes an alteration in this conformation. This conformation difference affects also the migration speed in the gel electrophoresis and new band or heteroduplex bands emerge. PCR products of three regions amplified to study the $\mathrm{G}_{\mathrm{i} 2 \alpha}$ mutations were incubated with denaturizing buffer containing 95\%-formamide, $10-\mathrm{mM}$ $\mathrm{NaOH}, 0.05 \%$-Bromophenol blue and $0.05 \%$ xylen cyanol at $95^{\circ} \mathrm{C}$ for five (5) minutes. Electrophoresis was applied to samples with glycerol in 6\%-non-denaturizing polyacrylamide gels at $250 \mathrm{~V}$ for five (5) hours for longer region, at $250 \mathrm{~V}$ for two (2) hours for other regions by using 0.6X TEB buffer. Gels were fixed with $10 \%$-ethanol and 5\%-acetic acid and were stained with $0.1 \%$-silver nitrate, the reaction was ceased by $0.75 \%$-sodium carbonate after the bands were revealed with $1.5 \%$ $\mathrm{NaOH} / 0.15 \%$-formaldehyde.

\section{Statistical analysis}

Data were presented as means \pm standard deviations. For statistical evaluation, SPSS 
10.00 (Statistical Package for Social Sciences) statistics software was used. Due to the number of subjects and due to the used techniques, data were evaluated through Kruskall-Wallis, Friedman and Mann-Whitney U tests.

\section{RESULTS}

The mean ages of the study groups were determined as $58.85 \pm 9.23$ for Group 1, as $48.77 \pm 9.32$ for Group 2 and, as $43.08 \pm 11.74$ for Group 3. When the mean ages were compared no statistically significant difference was found ( $p>0.05)$. The means of the measured serum values were shown in Table 1 . When both groups were compared with control, significant difference was observed between the melatonin values at 12:00 AM and at 6:00 $\mathrm{AM} p<0.05$. In order to clarify from which group or groups the difference between groups is resulted, MannWhitney U test was used. When the melatonin values of the patients in Group 1 and Group 2 were compared with respect to hours, no
PALABIYIK O., et al.

significant difference could be found between them $p>0.05$. When group 1 and group 3 were compared, significant difference was found between melatonin values at 12:00 AM and at 6:00 AM $\mathrm{p}<0.05$. When group 2 and group 3 were compared, significant difference was found between melatonin values at 12:00 AM and at 6:00 AM p<0.05. Whether the mean melatonin values of the patients and those of controls varied with respect to hours or not was investigated. Significant difference was found according to the obtained results $\mathrm{p}<0.05$. In order to identify gip mutations related with $\mathrm{G}_{\mathrm{i} 2 \alpha}$, the concentrations and the purity degrees of the DNAs isolated from the tissue samples were evaluated at $260 \mathrm{~nm}$ and at $280 \mathrm{~nm}$. The images of the PCR products of the amplified regions under UV light were shown in Figure 1-3. The image of the PCR products within the nondenaturizing polyacrylamide gels was shown in Figure 4.

Table 1. Gruplara Göre Melatonin Ortalama Değerleri

\begin{tabular}{|c|c|c|c|c|c|}
\hline \multirow{2}{*}{ Grup } & \multicolumn{5}{|c|}{ Saatlere Göre Melatonin Değerleri } \\
\hline & saat $22^{00}$ & saat $24^{00}$ & saat $02^{00}$ & Saat $04^{00}$ & saat $06^{00}$ \\
\hline Grup 1 & $66.99 \pm 97.09$ & $62.35 \pm 61.78$ & $62.72 \pm 67.17$ & $42.99 \pm 45.10$ & $62.54 \pm 62.33$ \\
\hline Grup 2 & $74.96 \pm 103.77$ & $62.92 \pm 69.11$ & $44.00 \pm 55.79$ & $50.58 \pm 62.99$ & $58.16 \pm 73.84$ \\
\hline Grup 3 & $11.89 \pm 10.75$ & $12.01 \pm 8.58$ & \begin{tabular}{|l}
$58.91 \pm 63.98$ \\
\end{tabular} & $72.65 \pm 66.66$ & $12.37 \pm 8.34$ \\
\hline $\mathbf{X}^{2}$ & 4.222 & 13.019 & 1.088 & 1.193 & 11.136 \\
\hline $\mathbf{p}^{*}$ & 0.121 & 0.001 & 0.581 & 0.551 & 0.004 \\
\hline
\end{tabular}

Data were presented as means \pm standard deviations. ${ }^{*}$ Kruskall-Wallis testi, $\mathrm{p} \leq 0.05$.

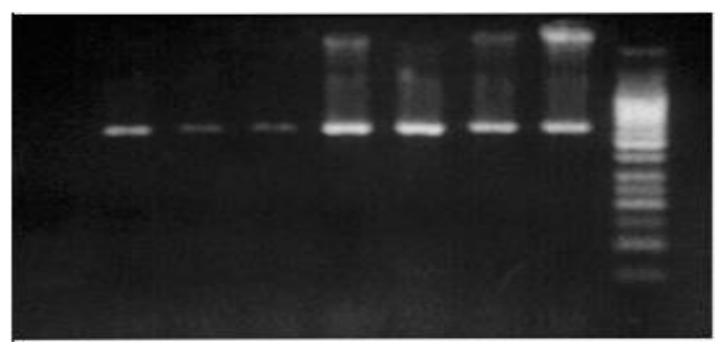

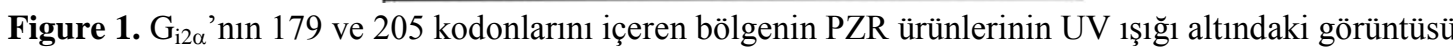

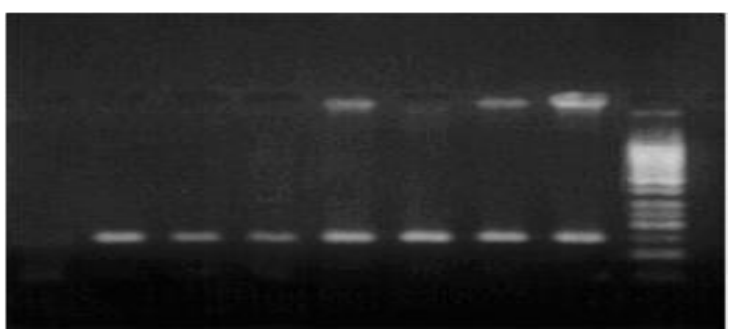

Figure 2. $G_{\mathrm{i} 2 \alpha}$ 'nın 179 kodonunu içeren bölgenin PZR ürünlerinin UV 1ş1ğı altındaki görüntüsü

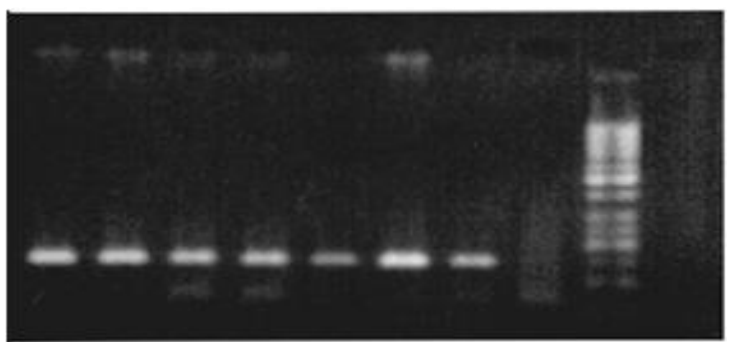

Figure 3. G i2 $_{\alpha}$ 'nın 205 kodonunu içeren bölgenin PZR ürünlerinin UV 1ş1ğı altındaki görüntüsü 


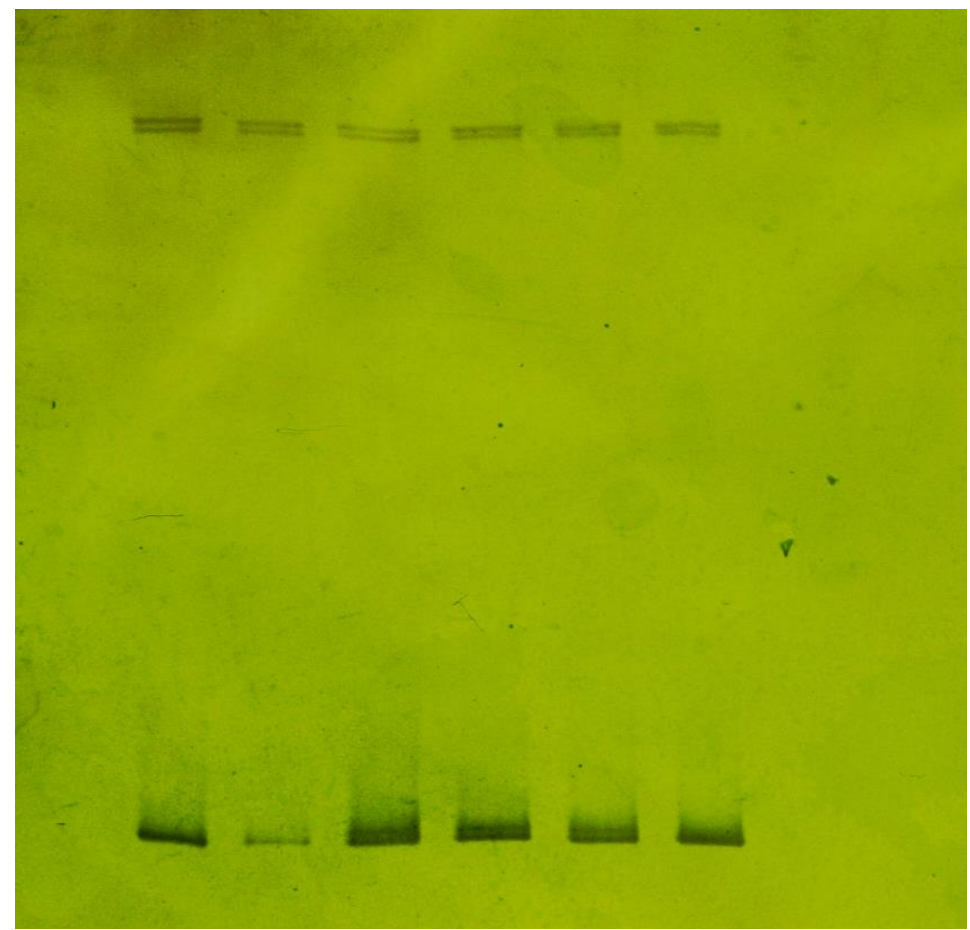

Figure 4. 179.ve 205. kodonları içeren over Ca hastalarının SSCP ürünlerinin görüntüsü.

\section{DISCUSSION}

In this study, the plasma melatonin levels of the breast cancer and ovary cancer patients were compared with healthy individuals. Furthermore, the potential of mutation $G_{i 2 \alpha}$ (gip) at the disease mechanism was studied in order to clarify the role of $G$ proteins. Pineal gland and the effects of the melatonin being the substance secreted by pineal gland known as the most important substance constitute an important focus of interest. Thus, there is an intense knowledge concerning the effects of melatonin in several processes. Melatonin synthesis, its secretion and its plasma level may vary due to the many factors such as ambient light, age of the individual, season, ambient temperature, hormones and cancer. In our study, it was seen that there is an increase in serum melatonin levels in healthy group during the night and a reduction in the earlier hours of the morning as reported in the literature. In the serum melatonin levels of the patient groups increases and reductions were seen during the night. While a significant difference was found between the values of melatonin at 12:00 $\mathrm{AM}$ and at 6:00 $\mathrm{AM}$ when group 1 and group 3 were compared $(p<0.05)$, no difference was found between group 1 and group $2(p>0.05)$. It has been shown that there are probable relationships between the tumor development and melatonin [10, 11]. The suppression of pineal function plays role in the etiology of several cancer types [12-14]. Lissoni et al [18] divided into two groups the patients and they administrated melatonin (20 milligrams per day) every day besides chemotherapy to one group and they administrated only chemotherapy to other group in a study that they conducted including totally two hundred fifty (250) patients with metastatic tumor consisting of one hundred four (104) patients with gastric carcinoma, seventy seven (77) patients with breast carcinoma, forty two (42) patients with gastrointestinal carcinoma and twenty seven (27) patients with tumors belonging to head and neck region. At the end of the study, it was seen that survival time was prolonged in the group receiving chemotherapy and melatonin compared to the group receiving only chemotherapy. In addition its favorable effects similar to this effect, melatonin has a suppressive effect on the endocrine glands [19]. The reduction of melatonin concentrations in the circulation increases the estrogen and testosterone secretions from the gonads. There is a significant negative correlation between the estrogen receptor correlations of the tumor and the melatonin concentration in night [20]. As the melatonin level decreases, estrogen receptor concentration increases. Whether there is a relationship between the prolonged excess of estrogen and the unfavorable influence of melatonin on estrogen production in ovaries and between the development of ovary and breast cancer and the secretion of melatonin from pineal in the etiology of breast and ovary cancers have been studied with several conducted studies [20].

In a study conducted by Bartsch et al [10] on patients with breast and ovary cancer, it was seen that tumor was inhibited in some patients when $10^{-8}$ to $10^{-10}$-Molar melatonin was administrated. In a study conducted by Ram et 
al [12] with estrogen receptor (+)-patients with breast carcinoma also, significant results have been obtained about the effects of tumor on melatonin secretion. In our presented study, it was found that the rhythm of melatonin secretion varies in significant level in patient groups with ovary and breast carcinoma compared to the healthy individuals selected in convenient age to these patients similarly to the literature. However, since the number in the patient groups and in control group was not sufficient for the statistical evaluation, non-parametric tests were used. The requirement of taking blood samples from the study groups at 10:00 PM, at 12:00 $\mathrm{AM}$, at 02:00 $\mathrm{AM}$, at 04:00 $\mathrm{AM}$ and at 06:00 during the night and the expensive price of melatonin reagent prevented us to conduct the study with more patients. Therefore, whether there is a relationship between the breast and ovary cancer and the rhythm of melatonin secretion or not could not be clarified in our study.

$\mathrm{G}$ proteins constitute a protein family mediating the generation of intracellular secondary messengers by binding the cellular surface receptors and intracellular effector molecules to each other. These heterotrimeric proteins built in $\alpha, \beta, \gamma$ subunits may be found in two separate conformations such as GDPbound active form and GDP-bound inactive form. In resting state, $\alpha$-subunit of the heterotrimer of G-protein is in GDP-bound state. When it is converted into GTP-bound active state, $\alpha$-subunit is separated from $\beta \gamma$ complex. Afterwards, it stimulates intracellular effector molecules and GTP hydrolyzed into GDP by means of natural GTPase activity of $\alpha$-subunits and it returns again into inactive state. $G$ proteins mediate many biochemical interactions via the receptors that they are clamped. As a result of the activation of adenilate cyclase enzyme by means of $G$ protein, either cAMP level increases or $\mathrm{Ca}^{+2}$ channels are activated. By virtue of $G_{i}$ protein, adenilate cyclase enzyme is suppressed and cAMP level is decreased and, $\mathrm{K}^{+}$channels are open. By virtue of $\mathrm{G}_{\mathrm{q}}$ protein, phospholipase $\mathrm{C}-\beta$ separates PIP2 into IP3 and DAG by becoming active.

It is suggested that endocrine tumors are formed as a result of the collection of genetic alterations impairing the normal cell growth and differentiation. Mutational alterations which are commonly observed and which are considered as the basis of the human carcinogenesis are the point mutations in the p53 tumor suppressing gene and in ras protooncogen. But the fact that the mechanism of carcinogenesis has not been clarified yet and that many receptors being clamped to $G$ protein and $G$ protein have roles in the control of cell growth suggest that mutations in the genes encoding these proteins may be one of the factors playing role in the formation of human tumors. Mutations that continuously activate $G \alpha_{s}$ and $G_{i 2 \alpha}$ by suppressing internal GTPase activity in the human endocrine tumors have been found. In a study conducted by Yoshimoto et al [19], $\mathrm{G}_{\mathrm{s \alpha}}$ mutations were found in four (4) of the forty three (43) patients with hypophysis adenoma. In ovary and adrenal cortex tumors also, gip oncogen has been identified. Even though the role of gip oncogene in tumor formation is not clear, it is suggested that it can transform several cell types. In human tumors, gip mutations belonging to $\alpha_{2 \mathrm{i}}$ have been found. In a study conducted by Lyons et al [21] concerning human ovary tumors, mutations related with $\mathrm{G}_{\mathrm{i} 2 \alpha}$ were found in eighteen (18) of forty two (42) patients. In the second stage of our study, samples of tumor tissues of the patients with ovary cancer and those of patients with breast cancer were studied. The region containing both codons with number 179 and 205 of $G_{i 2 \alpha}$ and the regions containing separately codons with number 179 and 205 were amplified by using specific primaries by means of PCR method. Mutations were identified with Single Strand Conformation Polymorphism (SSCP) method. In conclusion, gip mutations were found in the DNA samples of ovary carcinoma $(15 \%)$ and breast carcinoma (7\%) tumors.

The results of our study suggest that the rhythm of melatonin secretion is unfavorably affected in patients with breast cancer and ovary cancer. The results are consistent with the studies supporting that the reduction in melatonin increases the development of endocrine tumors. Based upon these results, whether the alterations of melatonin in circadian rhythm may be helpful in detecting the presence of tumor in earlier period or not may be studied by increasing the number of patients.

In other section of our study, gip mutations (ovary carcinoma (15\%) and breast carcinoma (7\%)) were detected by isolating DNA from tissues with tumor of the patients with either ovary carcinoma or breast carcinoma. In the future, the study is considered to continue by developing more.

\section{CONCLUSION}

Melatonin works through distinct second messenger pathways to reduce cellular 
proliferation and to induce cellular differentiation. G protein-coupled receptors, including the Melatonin receptors, exist in living cells. Melatonin is effective in suppressing neoplastic growth in a variety of tumors like breast and ovarian cancer.

\section{ACKNOWLEDGEMENT}

This study is funded by Trakya University, The Faculty of Medicine, Scientific Research Projects Unit (TÜBAP 2004-451).

\section{REFERENCES}

1. Reiter, R.J., Pineal melatonin: cell biology of its synthesis and of its physiological interactions. Endocr Rev, 1991. 12(2): p. 151-80.

2. Pandi-Perumal, S.R., et al., Role of the melatonin system in the control of sleep: therapeutic implications. CNS Drugs, 2007. 21(12): p. 995-1018.

3. Cohen, M., R.A. Small, and A. Brzezinski, Hypotheses: melatonin/steroid combination contraceptives will prevent breast cancer. Breast Cancer Res Treat, 1995. 33(3): p. 257-64.

4. Borjigin, J., X. Li, and S.H. Snyder, The pineal gland and melatonin: molecular and pharmacologic regulation. Annu Rev Pharmacol Toxicol, 1999. 39: p. 53-65.

5. Morgan, P.J., et al., Melatonin receptors: localization, molecular pharmacology and physiological significance. Neurochem Int, 1994. 24(2): p. 101-46.

6. Witt-Enderby, P.A. and M.L. Dubocovich, Characterization and regulation of the human ML1A melatonin receptor stably expressed in Chinese hamster ovary cells. Mol Pharmacol, 1996. 50(1): p. 166-74.

7. Fukuhara, S., et al., Signaling from G protein-coupled receptors to ERK5/Big MAPK 1 involves Galpha $q$ and Galpha $12 / 13$ families of heterotrimeric $G$ proteins. Evidence for the existence of a novel Ras AND Rho-independent pathway. J Biol Chem, 2000. 275(28): p. 21730-6.

8. Mundell, S.J. and J.L. Benovic, Selective regulation of endogenous $G$ protein-coupled receptors by arrestins in HEK293 cells. J Biol Chem, 2000. 275(17): p. 12900-8.

9. Sanchez-Barcelo, E.J., et al., Melatoninestrogen interactions in breast cancer. $\mathbf{J}$ Pineal Res, 2005. 38(4): p. 217-22.

10.Bartsch, H., et al., Effect of melatonin and pineal extracts on human ovarian and mammary tumor cells in a chemosensitivity assay. Life Sci, 2000. 67(24): p. 2953-60.

11.Gholami, M., et al., Effect of Melatonin on the Expression of Apoptotic Genes in Vitrified-thawed Spermatogonia Stem Cells Type A of 6-Day-Old Mice. Iran J Basic Med Sci, 2013. 16(8): p. 906-9.

12.Ram, P.T., et al., Involvement of the mt1 melatonin receptor in human breast cancer. Cancer Lett, 2002. 179(2): p. 141-50.

13.Futagami, M., et al., Effects of melatonin on the proliferation and cisdiamminedichloroplatinum (CDDP) sensitivity of cultured human ovarian cancer cells. Gynecol Oncol, 2001. 82(3): p. 544-9.

14.Shiu, S.Y., et al., Melatonin slowed the early biochemical progression of hormonerefractory prostate cancer in a patient whose prostate tumor tissue expressed MT1 receptor subtype. J Pineal Res, 2003. 35(3): p. 177-82.

15.Davis, S. and D.K. Mirick, Circadian disruption, shift work and the risk of cancer: a summary of the evidence and studies in Seattle. Cancer Causes Control, 2006. 17(4): p. 539-45.

16.Schernhammer, E.S. and S.E. Hankinson, Urinary melatonin levels and breast cancer risk. J Natl Cancer Inst, 2005. 97(14): p. 1084-7.

17.Schernhammer, E.S. and K. Schulmeister, Melatonin and cancer risk: does light at night compromise physiologic cancer protection by lowering serum melatonin levels? Br J Cancer, 2004. 90(5): p. 941-3.

18.Lissoni, P., et al., Decreased toxicity and increased efficacy of cancer chemotherapy using the pineal hormone melatonin in metastatic solid tumour patients with poor clinical status. Eur J Cancer, 1999. 35(12): p. 1688-92.

19.Cos, S., et al., Estrogen-signaling pathway: a link between breast cancer and melatonin oncostatic actions. Cancer Detect Prev, 2006. 30(2): p. 118-28.

20.Ram, P.T., et al., Estrogen receptor transactivation in MCF-7 breast cancer cells by melatonin and growth factors. Mol Cell Endocrinol, 1998. 141(1-2): p. 53-64.

21.Lyons, J., et al., Two G protein oncogenes in human endocrine tumors. Science, 1990. 249(4969): p. 655-9. 